\title{
Invited Review: Essential Oils as Modifiers of Rumen Microbial Fermentation
}

\author{
S. Calsamiglia, ${ }^{1}$ M. Busquet, P. W. Cardozo, L. Castillejos, and A. Ferret \\ Grup de Recerca en Nutrició, Maneig i Benestar Animal, Departament de Ciència Animal i dels Aliments, \\ Universitat Autònoma de Barcelona, 08193-Bellaterra, Spain
}

\begin{abstract}
Microorganisms in the rumen degrade nutrients to produce volatile fatty acids and synthesize microbial protein as an energy and protein supply for the ruminant, respectively. However, this fermentation process has energy (losses of methane) and protein (losses of ammonia $\mathrm{N}$ ) inefficiencies that may limit production performance and contribute to the release of pollutants to the environment. Antibiotic ionophores have been very successful in reducing these energy and protein losses in the rumen, but the use of antibiotics in animal feeds is facing reduced social acceptance, and their use has been banned in the European Union since January 2006. For this reason, scientists have become interested in evaluating other alternatives to control specific microbial populations to modulate rumen fermentation. Essential oils can interact with microbial cell membranes and inhibit the growth of some gram-positive and gram-negative bacteria. As a result of such inhibition, the addition of some plant extracts to the rumen results in an inhibition of deamination and methanogenesis, resulting in lower ammonia $\mathrm{N}$, methane, and acetate, and in higher propionate and butyrate concentrations. Results have indicated that garlic oil, cinnamaldehyde (the main active component of cinnamon oil), eugenol (the main active component of the clove bud), capsaicin (the active component of hot peppers), and anise oil, among others, may increase propionate production, reduce acetate or methane production, and modify proteolysis, peptidolysis, or deamination in the rumen. However, the effects of some of these essential oils are $\mathrm{pH}$ and diet dependent, and their use may be beneficial only under specific conditions and production systems. For example, capsaicin appears to have small effects in high-forage diets, whereas the changes observed in high-concentrate diets (increases in dry matter intake and total VFA, and reduction in the acetate-
\end{abstract}

Received October 4, 2006.

Accepted January 11, 2007.

${ }^{1}$ Corresponding author: sergio.calsamiglia@uab.es to-propionate ratio and ammonia $\mathrm{N}$ concentration) may be beneficial. Because plant extracts may act at different levels in the carbohydrate and protein degradation pathways, their careful selection and combination may provide a useful tool to manipulate rumen microbial fermentation effectively. However, additional research is required to establish the optimal dose in vivo in units of the active component, to consider the potential adaptation of microbial populations to their activities, to examine the presence of residues in the products (milk or meat), and to demonstrate improvements in animal performance.

Key words: plant extract, rumen fermentation

\section{INTRODUCTION}

Ruminants establish a symbiotic relationship with rumen microorganisms by which the animal provides nutrients and optimal environmental conditions for the fermentation of feeds, and microorganisms degrade fiber and synthesize microbial protein as an energy and protein supply for the animal, respectively. However, this symbiotic relationship has energy (losses of methane) and protein (losses of ammonia $\mathrm{N}$ ) inefficiencies (Van Nevel and Demeyer, 1988). These losses not only reduce production performance, but also contribute to the release of pollutants to the environment (Tamminga, 1996). Ruminant nutritionists have long been interested in modulating the competition among different microbial populations with the objective of improving the efficiency of energy and protein utilization in the rumen. This has been achieved through the optimization of diet formulations and the utilization of feed additives that modify the environment and enhance or inhibit specific microbial populations (Calsamiglia et al., 2006). Antibiotic ionophores have been very successful in reducing these energy and protein losses in the rumen (Van Nevel and Demeyer, 1988). However, the use of antibiotics in animal feeds is facing reduced social acceptance because of the appearance of residues and resistant strains of bacteria, and their use has been banned in the European Union since January 2006 (Directive 1831/2003/CEE, European Commission, 2003). 
For this reason, scientists have become interested in evaluating other alternatives to modulate rumen fermentation, including the use of yeasts, organic acids, plant extracts, probiotics, and antibodies (Calsamiglia et al., 2006).

Plants produce an extensive variety of organic compounds derived from the secondary metabolism that seem to have no direct function in their growth and development (Balandrin and Klocke, 1985). Over the years, these substances have been considered waste products of the primary metabolism. However, they are responsible for the odor and color of plants and spices, have important ecological functions as chemical messengers between the plant and its environment, and often exhibit antimicrobial activity against a wide range of bacteria, yeasts, and molds (Gershenzon and Croteau, 1991). These secondary metabolites are difficult to classify because their metabolic pathways of synthesis and their properties and mechanisms of action are often overlapped, and differences are difficult to ascertain. However, they can generally be structured into 3 groups: saponins, tannins, and essential oils. The effects and mechanisms of action of saponins and tannins on rumen microbial fermentation have been extensively researched, and reviews have recently been published (Cheeke, 1999; Min et al., 2003; Piacente et al., 2005). In contrast, information on the effect of essential oils on rumen microbial fermentation is very limited, and only in recent years has a reasonable body of knowledge been published. The objective of the present paper is to review current knowledge and assess the potential benefits of essential oils and their active components as modifiers of rumen microbial fermentation.

\section{ORIGIN AND CLASSIFICATION OF ESSENTIAL OILS}

Essential oils are blends of secondary metabolites obtained from the plant volatile fraction by steam distillation (Gershenzon and Croteau, 1991). The term "essential" derives from "essence," which means smell or taste, and relates to the property of these substances of providing specific flavors and odors to many plants. They are characterized as having a very diverse composition, nature, and activities. The most important active compounds are included in 2 chemical groups: terpenoids (monoterpenoids and sesquiterpenoids) and phenylpropanoids. These 2 groups originate from different precursors of the primary metabolism and are synthesized through separate metabolic pathways (Figure 1).

Terpenoids are the more numerous and diversified group of plant secondary metabolites, and around 15,000 different compounds have already been described in the literature (Gershenzon and Croteau,
1991). These compounds are characterized as deriving from a basic structure of 5 carbons $\left(\mathrm{C}_{5} \mathrm{H}_{8}\right)$, commonly called an isoprene unit, and are classified depending on the number of these units in its skeleton. Within terpenoids, the most important components of essential oils of the majority of plants belong to the monoterpenoid and sesquiterpenoid families (Figures 1 and 2; Gershenzon and Croteau, 1991).

Phenylpropanoids are not the most common compounds of essential oils, but some plants have them in significant proportions. The term "phenylpropanoid" refers to compounds with a chain of 3 carbons bound to an aromatic ring of 6 carbons. Phenylpropanoids (Figures 1 and 2) derive mainly from phenylalanine (an aromatic AA) synthesized by the shikimate metabolic pathway, which is only functional in microorganisms and plants (Sangwan et al., 2001).

\section{BIOLOGICAL PROPERTIES AND MECHANISMS OF ACTION OF ESSENTIAL OILS}

Essential oils have a wide variety of effects on health, including positive effects on cardiovascular diseases, some tumors, inflammatory processes, and, in general, diseases in which the uncontrolled proliferation of free radicals is very damaging (Harborne and Williams, 2000; Reddy et al., 2003; Trouillas et al., 2003). These properties depend on their ability to scavenge free radicals, inhibit peroxidation of membrane lipids, chelate metals, and stimulate the activity of antioxidant enzymes (Gutiérrez et al., 2003; Lee et al., 2003). However, the most important activities of these compounds are as antiseptics and antimicrobials. The antiseptic properties of many plants have been known since antiquity. The Chinese began to use plants in medicinal therapies 5,000 yr ago, and in $1550 \mathrm{BC}$, the Egyptians used plants for food preservation and in mummification ceremonies (Davidson and Naidu, 2000). However, the first scientific evidence describing their antimicrobial properties did not appear until the beginning of the 20th century (Hoffmann and Evans, 1911). Since then, many essential oil compounds with strong antimicrobial activities have been studied (Burt, 2004; Table 1).

Terpenoids and phenylpropanoids develop their action against bacteria through interacting with the cell membrane (Griffin et al., 1999; Davidson and Naidu, 2000; Dorman and Deans, 2000). At least part of this activity is due to the hydrophobic nature of the cyclic hydrocarbons, which allows them to interact with cell membranes and accumulate in the lipidic bilayer of bacteria, occupying a space between the chains of fatty acids (Sikkema et al., 1994; Ultee et al., 1999). This interaction causes conformational changes in the membrane structure, resulting in its fluidification and 


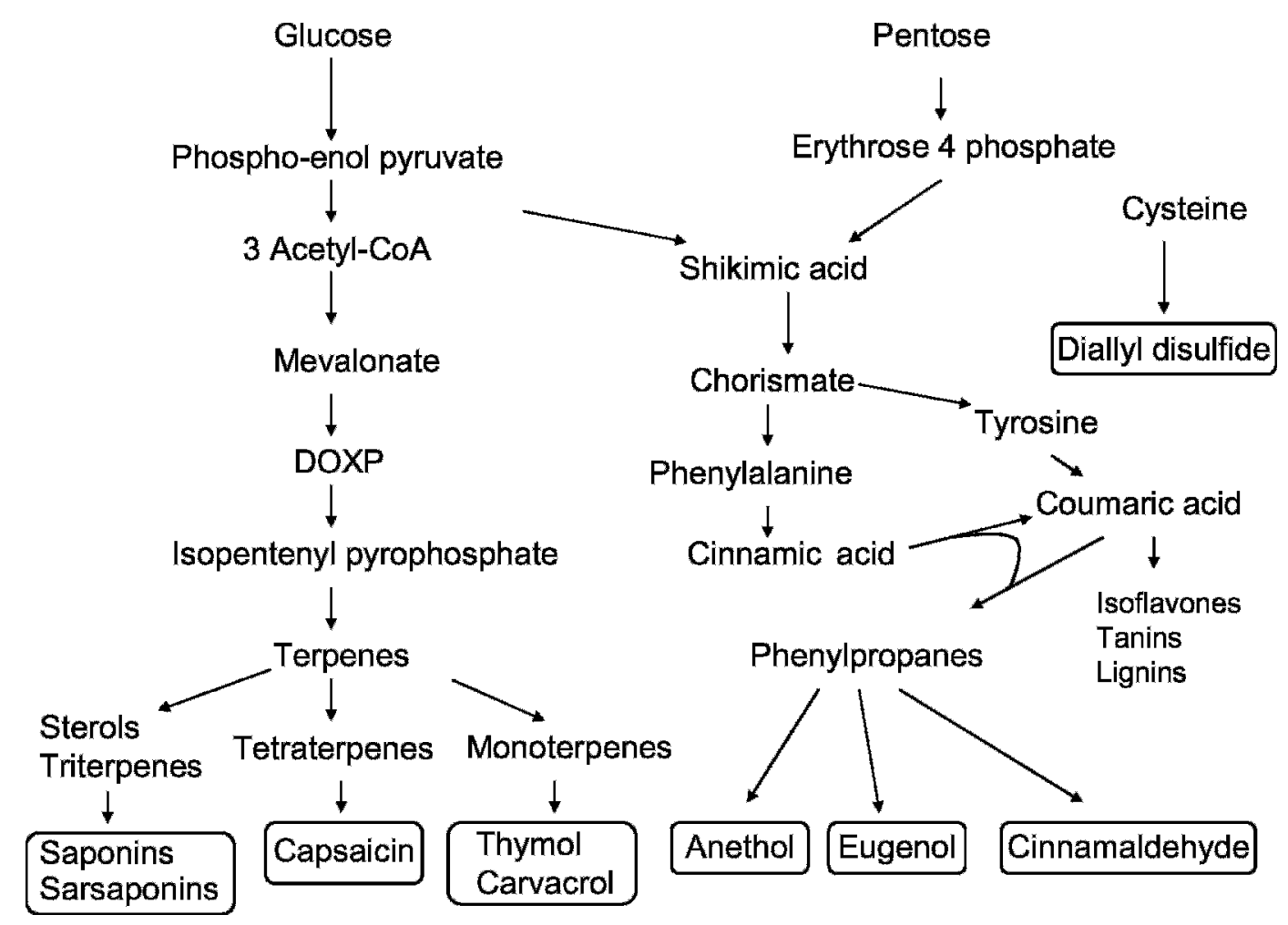

Figure 1. Metabolic pathways of the biosynthesis of the main plant extract active components.

expansion (Griffin et al., 1999). The loss of membrane stability results in the leakage of ions across the cell membrane, which causes a decrease in the transmembrane ionic gradient. In most cases, bacteria can counterbalance these effects by using ionic pumps and cell death does not occur, but large amounts of energy are diverted to this function and bacterial growth is slowed down (Griffin et al., 1999; Ultee et al., 1999; Cox et al., 2001). In the context of continuous flow in the rumen, a change in growth rates results in changes in the proportion of rumen bacterial populations, resulting in changes in the fermentation profile. In general, the antimicrobial activity is highest in oxygenated cyclic hydrocarbons, and particularly in phenolic structures such as thymol and carvacrol, in which the hydroxyl group and the dislocated electrons allow for the interaction with water through hydrogen bridges as the main active site, making them particularly active against microorganisms (Griffin et al., 1999; Davidson and Naidu, 2000; Dorman and Deans, 2000; Cox et al., 2001). Ultee et al. (2002) proposed an alternative mechanism in which the hydroxyl group of phenols acts as a transmembrane carrier of monovalent cations and protons, such as ionophore antibiotics (Figure 3). Ultee et al. (2002) also observed that this hypothesis was true only in the hydroxyl groups of aromatic compounds, because compounds such as menthol (exactly equal to carvacrol but not aromatic) do not result in the same inhibitory effects. This is probably due to the presence of a dislocated electron system and the high acidity of phenols and, consequently, to the ability of the hydroxyl group to release its proton.

These mechanisms of action should be more effective against gram-positive bacteria, where the cell membrane can interact directly with hydrophobic compounds of essential oils (Smith-Palmer et al., 1998; Chao and Young, 2000; Cimanga et al., 2002). In contrast, the external cell wall around the cell membrane of gram-negative bacteria is hydrophilic and does not allow the entrance of lipophilic substances. Like monensin, most compounds of essential oils are lipophilic and cannot penetrate into the membrane of gram-negative bacteria (Cox et al., 2001; Cimanga et al., 2002). However, the external membrane of gram-negative bacteria is not completely impermeable to hydrophobic substances, and low molecular weight molecules can interact with water (through hydrogen bridges), cross the cell wall slowly by diffusion through the layer of lipopolysaccharides or through membrane proteins, and interact with the lipid bilayer of cells (Griffin et al., 1999; Dorman and Deans, 2000). This is the case for some aromatic hydrocarbons such as carvacrol and thy- 
A

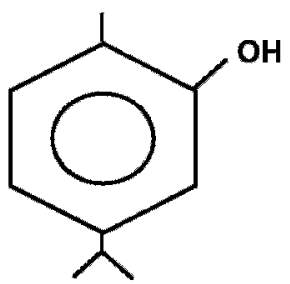

Carvacrol

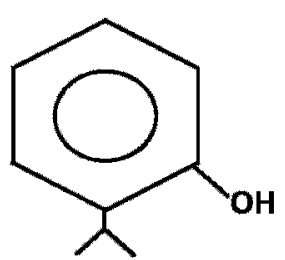

Thymol

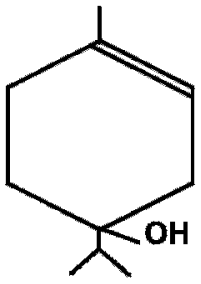

Terpinen-4-ol

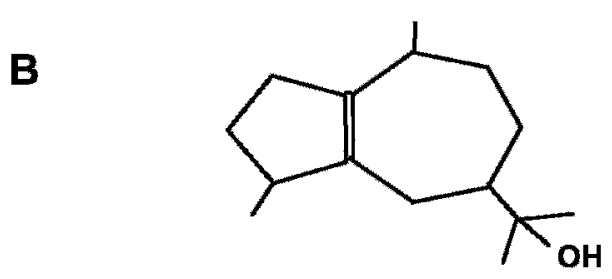

Guaiol

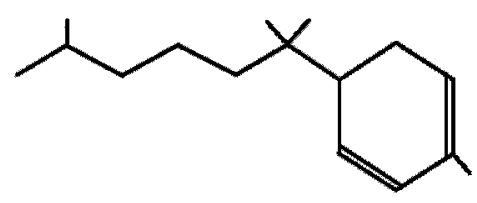

Zingiberene

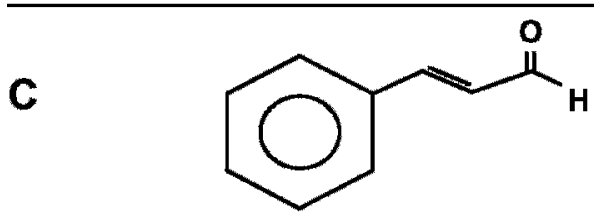

Cinnamaldehyde

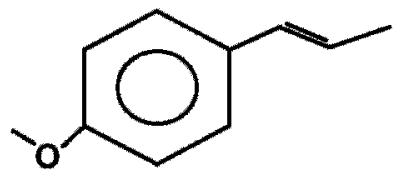

Anethole

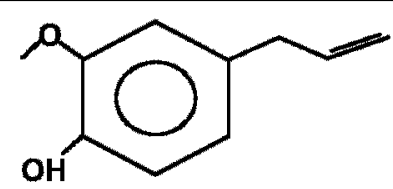

Eugenol<smiles>COc1cc(CNC(=O)CCCC/C=C/C(C)C)ccc1O</smiles>

Capsaicin

Figure 2. The main monoterpenoid (A), sesquiterpenoid (B), and phenylpropanoid (C) components of essential oils.

mol (Helander et al., 1998). On the other hand, Helander et al. (1998) also reported the capacity of thymol and carvacrol to disintegrate the external membrane of gram-negative bacteria, and observed the release of membrane lipopolysaccharides and the increased permeability of the cytoplasmic membrane. Therefore, the small molecular weight of these compounds may allow them to be active in gram-positive and gram-negative bacteria. Unfortunately, this property reduces the selectivity of these compounds against specific populations, making the modulation of rumen microbial fermentation more difficult.

Although the main action of essential oils as antimicrobial seems to be centered in its activity on the cell membrane, this is not the only mechanism of action. Gustafson and Bowen (1997) reported the potential of essential oils to coagulate some cell constituents, probably by denaturation of proteins. Numerous studies have also reported the capacity of some phenolic and nonphenolic compounds of essential oils to interact with chemical groups of proteins and other biologically active molecules, such as enzymes (Juven et al., 1994). In general, phenols interact with proteins through hydrogen bridges and ionic or hydrophobic interactions (Prescott et al., 2004), whereas nonphenolic compounds interact through another functional group, such as the carbonyl group of cinnamaldehyde (Ouattara et al., 1997). Other aldehyde compounds may also interact with nucleic acids and proteins, resulting in their inactivation, probably using crossed bridges or by alkylation (Prescott et al., 2004). For example, Wendakoon and Sakaguchi (1995) demonstrated that the active components of essentials oils of cinnamon and cloves could bind proteins and inhibit the enzymatic activity of Enterobacter aerogenes. 
Table 1. Essential oils with antimicrobial activity, their main active components, and susceptible microorganisms

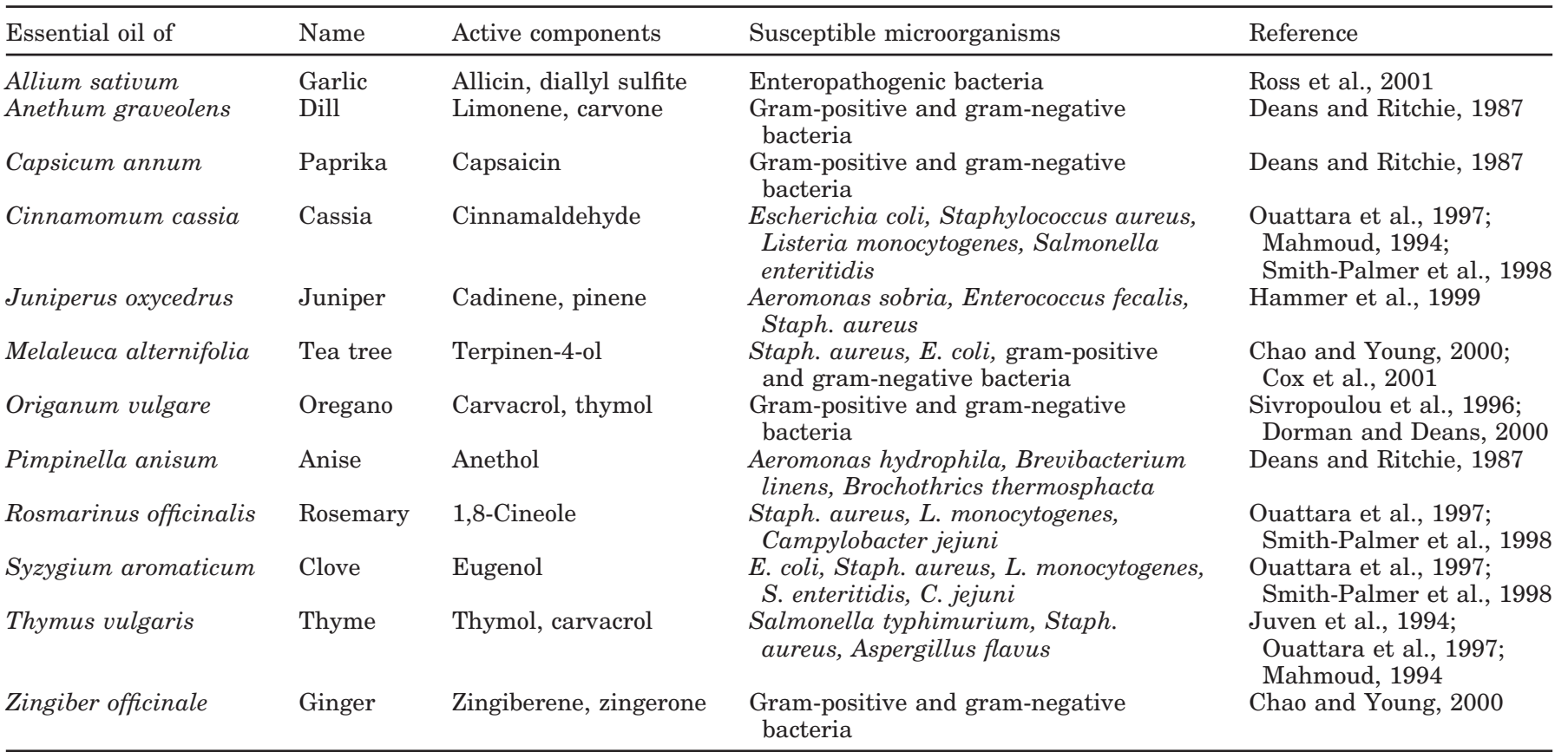

The essential oil of garlic is a special case, because many compounds of this oil are not in the whole plant, like most other essentials oils, but are produced from thiosulfates during the steam treatment of the plant (Pentz and Siegers, 1996). They are very active against a wide range of gram-positive and gram-negative bacteria, fungi, parasites, and viruses (Reuter et al., 1996). Several mechanisms of action have been suggested to explain its antimicrobial activity, including inhibition of the synthesis of RNA, DNA, and proteins of the cell (Feldberg et al., 1988). However, the main antimicrobial mechanism appears to be related to its capacity to interact with the sulfhydryl groups (-SH) of other active compounds (Reuter et al., 1996). In fact, many studies have reported that the antimicrobial activity of allyl sulfur compounds of garlic oil increases with each additional S atom, and that the antimicrobial activity of garlic oil is more powerful than the activity of its main compounds individually, suggesting that the effect is the result of synergy among the different compounds (Reuter et al., 1996; O'Gara et al., 2000; Ross et al., 2001; Busquet et al., 2005b).

\section{EFFECTS OF ESSENTIAL OILS ON RUMINAL FERMENTATION}

Essential oils appear to be natural alternatives to the use of growth-promoter antibiotic additives in animal feeds. In fact, some experiments have demonstrated that the use of some plant extracts in swine and poultry increase daily weight gain similar to the results of antibiotic additives (Piva and Rossi, 1999; Kamel, 2001). However, studies with scientific evidence of the effect of essential oils on rumen microbial fermentation are limited.

Borchers (1965) was the first to report the potential benefit of essential oils on rumen microbial fermentation. Borchers observed that the addition of thymol (active compound of thyme and oregano) to rumen fluid in vitro resulted in the accumulation of $\mathrm{AA} \mathrm{N}$ and the reduction of ammonia $\mathrm{N}$ concentrations, suggesting that thymol inhibited deamination. Oh et al. (1967, 1968) hypothesized that the low palatability of some plants to ruminants could be due not only to organoleptic effects, but also to their negative effect on rumen microbial fermentation and nutrient digestion. In one study, Oh et al. (1967) evaluated the antimicrobial activity of the essential oil of Pseudostuga menziesii and its compounds using 24-h in vitro cultures with the ruminal fluid of deer and sheep. Results demonstrated that low levels of inclusion (4 to $8 \mathrm{~mL} / \mathrm{L}$ of liquid) had no effect on rumen microbial fermentation, but higher levels ( $12 \mathrm{~mL} / \mathrm{L}$ of liquid) reduced gas production during fermentation. When the main compounds isolated from the essential oil were used at similar doses $(3 \mathrm{~mL} / \mathrm{L}$ of liquid), the cyclic hydrocarbons (limonene, pinene) did not modify or sometimes stimulated microbial activity, but the oxygenated cyclic hydrocarbons and certain alcohols (terpinen-4-ol, $\alpha$-terpineol) inhibited microbial fermentation. In a second study, Oh et al. (1968) evalu- 


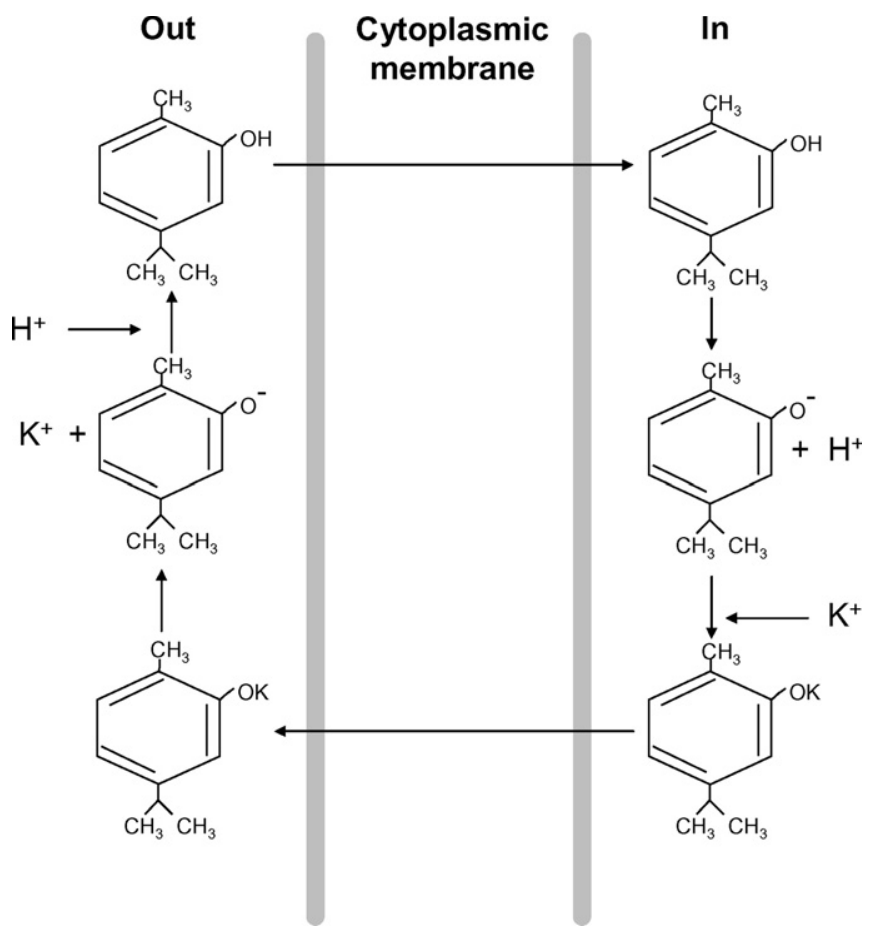

Figure 3. Hypothesized mechanism of action of carvacrol in the cytoplasmic membrane (Ultee et al., 2002). The undissociated carvacrol diffuses through the cytoplasmic membrane toward the cytoplasm and dissociates, thereby releasing its proton to the cytoplasm. Later, undissociated carvacrol returns by carrying a potassium ion (or another ion) from the cytoplasm to the extracellular medium. Carvacrol liberates this ion in the extracellular medium and recovers an additional hydrogen to close the cycle.

ated the antimicrobial activity of essential oils from relatively unpalatable plants, and although all had some degree of antimicrobial activity, the most active (significant decreases in gas and VFA production during fermentation) were those with a high content of oxygenated cyclic hydrocarbons. Nagy and Tengerdy (1968) also evaluated the sensitivity of ruminal microorganisms to the essential oil of Artemisia tridentate (main compound 1,8-cineole), because some evidence indicated that high intake of this plant resulted in digestive problems in wild deer. In general, high doses of this oil, added to in vitro cultures of rumen bacteria from deer, reduced total viable bacteria counts, and at the maximum dose (1.6 to $2 \mathrm{mg} / \mathrm{L}$ of culture medium), the only surviving species were small gram-negative microorganisms. However, at the beginning of the 1970s, authorization on the use of ionophore antibiotics as growth promoters stopped research on the use of essential oils in animal feeding, and few studies were conducted in the following $30 \mathrm{yr}$ (Broderick and Balthrop, 1979).

Since the announcement of the ban on antibiotics as feed additives in the European Union, there has been
Table 2. Content of main components of essential oils of 3 varieties of oregano ${ }^{1}$

\begin{tabular}{lccc}
\hline & \multicolumn{3}{c}{ Composition of essential oils, \% } \\
\cline { 2 - 4 } & $\begin{array}{c}\text { Origanum } \\
\text { Commercial } \\
\text { Components }\end{array}$ & $\begin{array}{c}\text { Origanum } \\
\text { hirtum }\end{array}$ & $\begin{array}{c}\text { Origanum } \\
\text { dictamnus }\end{array}$ \\
\hline$\gamma$-Terpinene & 1.32 & 2.07 & 11.41 \\
$p$-Cimene & 40.15 & 8.76 & 13.49 \\
Thymol & 31.80 & 2.45 & 0.44 \\
Carvacrol & 0.43 & 79.58 & 62.44 \\
\hline
\end{tabular}

${ }^{1}$ Adapted with permission from Sivropoulou et al. (1996). Copyright 1996 American Chemical Society.

renewed interest in studying the effects and mechanisms of action of essential oils on rumen microbial fermentation. In the last $6 \mathrm{yr}$, research has been published on the effects of more than 25 different plant extracts (Achillea millefolium, Arnica chamissonis, Betula alba, Dactylis glomerata, Eucalyptus globulus, Ginkgo biloba, Lavandula officinalis, Lespedeza capitata, Hypericum perforatum, Solidago virgaurea, Fagopyrum esculentum, Equisetum arvense, Salvia officinalis, Pimpinella anisum, Juniperus oxycedrus, Capsicum annuum, Cinnamonum cassia, Syzygium aromaticum, Anethum graveolens, Trigonella foenum graecum, Allium sativum, Zingiber officinale, Origanum vulgare, Melaleuca alternifolia, and Armoracia rusticana) on in vitro rumen microbial fermentation (Broudiscou et al., 2000, 2002; Cardozo et al., 2004, 2005; Mohammed et al., 2004; Busquet et al., 2005c, 2006). Among these, L. officinalis, S. virgaurea, and A. millefolium stimulated rumen fermentation and $E$. arvense, $A$. rusticana, and $S$. officinalis inhibited methanogenesis (Broudiscou et al., 2000, 2002; Mohammed et al., 2004). Others (C. cassia, A. sativum, and S. aromaticum) modified the production and profile of VFA, $\mathrm{N}$ metabolism, or both (Cardozo et al., 2004, 2005; Busquet et al., 2005c, 2006). However, there is considerable variation in the content of active compounds in these extracts because of variety in the cultivated plant, growing conditions, and processing methods, among other factors. For example, Sivropoulou et al. (1996) observed that the concentrations of thymol and carvacrol (active compounds of oregano) ranged from 0.44 to $31.8 \%$ and 0.43 to $79.6 \%$, respectively (Table 2 ), depending on the cultivar and processing methods. Large variations in the concentration of active components in rosemary oil (Rosmarinus officinalis; 2 to $25 \%$ of $\alpha$-pinene, and 3 to $89 \%$ of 1,8-cineole) and other plant extracts have also been reported (Marino et al., 2001; Burt, 2004). This variability generates confusion because the effects can be contradictory, according to the content of the active component in the extract and the dose used. Therefore, it is necessary either to report the concentrations of 
these active compounds in the plant extracts used in research, or to use pure products to define activities, doses, and mechanisms of action in an unequivocal form.

Only recently have the effects of pure, active components of essential oils on rumen microbial fermentation been studied. The first challenge is to define which potential effects are examined, and this may differ depending on the diet, animal, and production system. However, it is reasonable to start by identifying additives that increase propionate production and decrease acetate and methane production without reducing total VFA production, and additives that reduce proteolysis, peptidolysis, deamination, or their combination. A set of in vitro short-term batch fermentation studies has been used to screen for potentially useful extracts (Cardozo et al., 2005; Busquet et al., 2006; Castillejos et al., 2006), and selected oils and their active components have been studied in long-term continuous culture fermentation studies (Cardozo et al., 2004; Busquet et al., 2005a,b,c; Castillejos et al., 2006). These results have indicated that garlic oil, cinnamaldehyde (the main active component of cinnamon oil), eugenol (the active component of the clove bud), capsaicin (the active component of the hot pepper), and anethol (the active component of anise oil) improve the fermentation profile in continuous culture of rumen microorganisms, and they have been studied in depth in vitro and, in some cases, in vivo (Cardozo et al., 2006). Their effects are presented separately by their active components.

\section{Thymol}

Thymol is a monoterpene [5-methyl-2-(1-methylethyl)phenol; $\mathrm{C}_{10} \mathrm{H}_{14} \mathrm{O}$ ] with strong antimicrobial activity against a wide range of gram-positive and negative bacteria, and is one of the most well-researched active components of essential oils (Figure 1 and 2; Burt, 2004). Thyme (Thymus spp.) and oregano (Origanum spp.) oils contain large but variable quantities of thymol (Sivropoulou et al., 1996; Burt, 2004). Borchers (1965) was the first to report that the in vitro incubation of casein in rumen fluid with thymol $(1,000 \mathrm{mg} / \mathrm{L})$ resulted in an accumulation of $\mathrm{AA}$ and a reduction in ammonia $\mathrm{N}$ concentration, suggesting that deamination was inhibited. A similar conclusion was reached by Broderick and Balthrop (1979) after incubating rumen fluid with thymol in vitro. More recently, Evans and Martin (2000) reported that thymol affected the energy metabolism of 2 relevant rumen bacteria grown in pure culture: Streptococcus bovis and Selenomonas ruminantium. It reduced methane and lactate concentrations, although at higher doses it also reduced overall nutrient digestion and total VFA production, a clear indication that microbial metabolism was inhibited. This effect was attributed to the loss of integrity of the cell membrane and a reduction in the uptake of glucose. However, moderate doses (100 to $400 \mathrm{mg} / \mathrm{L}$ ) resulted in an increase in the acetate-to-propionate ratio. It is interesting to point out that $S$. ruminantium was more sensitive to thymol than $S$. bovis. This may result in an increased accumulation of lactic acid, because the production of lactate by $S$. bovis (a major lactic acid producer) may not be metabolized fast enough by $S$. ruminantium (a major lactic acid utilizer), and an objective of modifying rumen fermentation would likely be the contrary: to reduce $S$. bovis and to increase $S$. ruminantium to attempt to control the lactic acid concentration in the rumen. Castillejos et al. (2006) reported that low doses of thymol $(50 \mathrm{mg} / \mathrm{L})$ had no effects on in vitro rumen microbial fermentation, but at higher doses $(500 \mathrm{mg} / \mathrm{L})$ total VFA and ammonia $\mathrm{N}$ concentrations decreased, and the acetate-to-propionate ratio increased. Similar results were reported in a long-term continuous culture fermentation study, suggesting that the optimal dose of thymol is somewhere between 50 and $500 \mathrm{mg} / \mathrm{L}$. Furthermore, several in vitro studies have suggested that the effects of thymol are diet and $\mathrm{pH}$ dependent (Cardozo et al., 2005; Castillejos et al., 2006). Although Castillejos et al. (2006) reported that thymol increased the acetate-to-propionate ratio in a 60:40 alfalfa hay:concentrate diet at high $\mathrm{pH}$ (6.4), Cardozo et al. (2005) observed changes in the opposite direction (a reduction in the acetate-to-propionate ratio) when thymol was incubated in rumen fluid from cattle fed a 10:90 straw:concentrate (based on corn, barley, and soybean meal) diet at $\mathrm{pH}$ 5.5. Juven et al. (1994) previously reported that the antimicrobial effect of the essential oil of thyme increased as $\mathrm{pH}$ decreased from 6.5 to 5.5. It is likely that at lower $\mathrm{pH}$, the hydroxyl group may be nondissociated and becoming more hydrophobic, allowing an easier integration of the molecule with the lipid bilayer of the cell membrane. Therefore, it is important to define the conditions under which these additives are used to modify rumen microbial fermentation in the desired direction.

Compounds with phenolic structures, such as thymol, are more effective as antimicrobials in comparison with other nonphenolic secondary plant metabolites because of the presence of a hydroxyl group in the phenolic structure (Helander et al., 1998; Ultee et al., 2002). Furthermore, the small molecular weight of thymol allows it to gain access to the cell membrane through the pores of the external wall. The strong and widespectrum activity against gram-positive and gram-negative bacteria, the narrow margin of security between an optimal and a toxic dose, and the effects reported, which were not always in the desired direction (Castil- 
lejos et al., 2006), suggest that its antimicrobial activity may be too strong and nonspecific to modulate the fermentation in a complex microbial environment such as the rumen.

\section{Eugenol}

Eugenol (4-allyl-2-methoxyphenol; $\mathrm{C}_{10} \mathrm{H}_{12} \mathrm{O}_{2}$ ) is a phenolic compound (Figures 1 and 2 ) with wide-spectrum antimicrobial activity against gram-positive and gram-negative bacteria, and it is one of the main active components in clove bud (Eugenia caryophyllus or $S$. aromaticum) and cinnamon (C. cassia) oils (accounting for up to 85 and $8 \%$ of these oils, respectively; Davidson and Naidu, 2000). In a continuous culture study, low doses of clove bud oil ( $2.2 \mathrm{mg} / \mathrm{L})$ resulted in lower molar proportions of acetate and branched-chain VFA (BCVFA) and a higher molar proportion of propionate (Busquet et al., 2005c). Clove bud oil also affected $\mathrm{N}$ metabolism, increasing peptide $\mathrm{N}$ and numerically decreasing AA N concentrations, suggesting that it decreased the peptidolytic activity in the rumen. In an in vitro batch culture dose-response study, Busquet et al. (2006) confirmed that clove bud oil affected rumen fermentation, reducing total VFA and ammonia $\mathrm{N}$ concentrations and showing a linear increase in the molar proportion of propionate and a quadratic effect on the molar proportions of acetate and butyrate. In general terms, the effects of eugenol were similar to those reported for clove bud oil. The fermentation profile observed suggests that, when used at optimal doses, the efficiency of energy and protein utilization in the rumen was improved. The potential benefits of eugenol on rumen microbial fermentation were further tested in vitro by Castillejos et al. (2006) with 2 different types of diets. Data confirmed that in a 60:40 forage:concentrate dairy cattle diet based on alfalfa hay, corn grain, barley grain, and soybean meal, eugenol reduced ammonia $\mathrm{N}$ and BCVFA concentrations, suggesting that deamination was inhibited. Effects on the production and proportions of VFA were more variable. In contrast, in a 10:90 beef-type diet based on straw, corn grain, barley grain, and soybean meal, eugenol reduced the total VFA concentration and proportion of propionate, and increased the proportion of acetate and the acetate-to-propionate ratio. This fermentation profile may not be desirable for beef production. Therefore, it appears that eugenol may improve VFA production and the VFA profile as well as $\mathrm{N}$ utilization in the rumen of lactating animals, but the fermentation profile does not support its recommendation for beef cattle diets.

\section{Cinnamaldehyde}

Cinnamaldehyde (3-fenil-2-propenal phenol; $\mathrm{C}_{9} \mathrm{H}_{8} \mathrm{O}$ ), a phenylpropanoid with antimicrobial activity, is the main active component of cinnamon (C. cassia) oil, accounting for up to $75 \%$ of its composition (Figures 1 and 2). Cardozo et al. (2004), in a continuous culture experiment, were the first to suggest that cinnamon oil $(0.22 \mathrm{mg} / \mathrm{L}$ of rumen fluid) modified the $\mathrm{N}$ metabolism of rumen microorganisms by inhibiting peptidolysis, but the effects on VFA concentration were negligible. Higher doses $(3,000 \mathrm{mg} / \mathrm{L})$ of cinnamon oil and cinnamaldehyde decreased the total VFA and ammonia $\mathrm{N}$ concentrations, although cinnamaldehyde had stronger effects compared with cinnamon oil (Busquet et al., 2006). However, effects on the proportions of individual VFA were different, and although cinnamon oil increased acetate without affecting the molar proportions of propionate or butyrate, cinnamaldehyde increased propionate without affecting the acetate and butyrate proportions. These results suggest that, although cinnamaldehyde is the main and most active component in cinnamon oil, other substances within cinnamon oil may interact with cinnamaldehyde, although cinnamaldehyde resulted in a more desirable fermentation profile.

Busquet et al. (2005a,c) tested the effect of low doses of cinnamaldehyde $(1.4 \mathrm{mg} / \mathrm{L})$ in a long-term dual-flow continuous culture fermentation study and reported similar trends, in which cinnamaldehyde numerically decreased the molar proportion of acetate and numerically increased the proportion of butyrate, but differences did not reach significance. When higher doses (31.2 and $312 \mathrm{mg} / \mathrm{L}$ ) were used (Busquet et al., 2005a), cinnamaldehyde reduced the molar proportion of acetate and increased the molar proportions of propionate and butyrate. This fermentation profile is similar to that observed when antimethanogenic compounds, such as amicloral or carbon monoxide, were used to modify rumen microbial fermentation, suggesting that its mechanism of action may involve the inhibition of methanogenesis (Horton, 1980; Hino and Russell, 1985), but that hypothesis needs to be confirmed with experimental data. The effects of cinnamaldehyde on $\mathrm{N}$ metabolism were inconsistent. Although some studies reported changes in $\mathrm{N}$ metabolism (Cardozo et al., 2004; Busquet et al., 2005c), others found no effects (Busquet et al., 2005a). At least part of these inconsistencies may be related to the dose used. However, Ferme et al. (2004) reported that the addition of cinnamaldehyde to an in vitro rumen simulation system resulted in a reduction in Prevotella spp., a group of bacteria known to be involved in deamination, providing evidence of a mechanism of action. The antimicrobial activity of cinnamaldehyde is likely related to the reactivity of its carbonyl group (Wendakoon and Sakaguchi, 1995; Helander et al., 1998), but the exact mechanism of action is not known. Helander et al. (1998) observed that, in contrast 


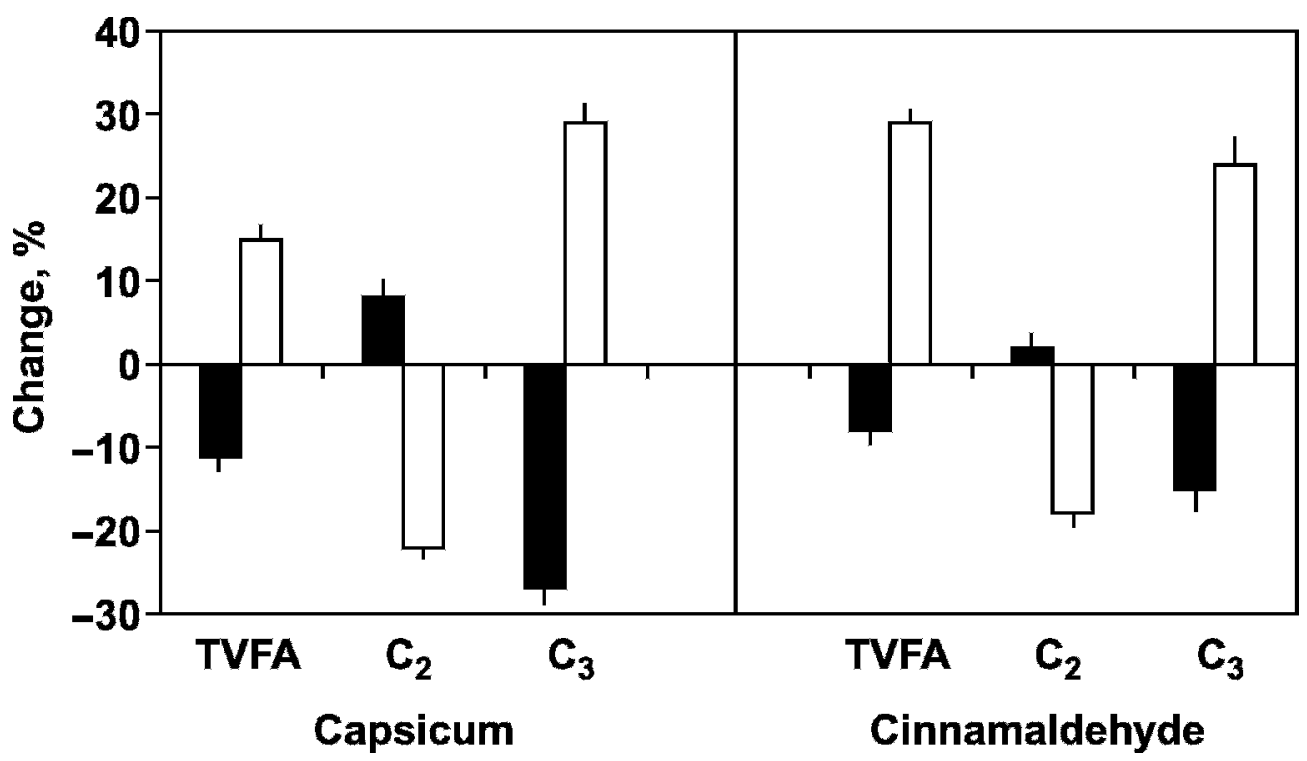

Figure 4. Percentage change and standard error in total VFA (TVFA), acetate $\left(\mathrm{C}_{2}\right)$, and propionate $\left(\mathrm{C}_{3}\right)$ caused by the incubation of rumen fluid of beef steers fed a 10 to 90 straw-to-concentrate diet at pH 7.0 ( $\square$ ) or pH 5.5 ( $\square$ ) in the presence of capsicum or cinnamaldehyde compared with a control. (Adapted from Cardozo et al., 2005.)

to other secondary plant metabolites (i.e., thymol or carvacrol), cinnamaldehyde did not affect membrane stability and suggested that its mechanism of action was related to its interaction with proteins in the periplasm or deeper parts of the cell (Nikaido, 1994).

Results presented in the previous discussion were conducted using rumen fluid from dairy cattle and a high-forage diet, but as demonstrated with other essential oils, the effects may change depending on the type of diet and pH. Cardozo et al. (2005) tested the effects of cinnamon oil and cinnamaldehyde in vitro using rumen fluid from beef cattle fed a 10:90 forage-to-concentrate diet. At pH 7.0, cinnamon oil and cinnamaldehyde resulted in a higher acetate-to-propionate ratio and a lower total VFA concentration, suggesting a lower efficiency of nutrient utilization in the rumen. In contrast, at $\mathrm{pH}$ 5.5, total VFA increased, and the ammonia $\mathrm{N}$ concentration and the acetate:propionate ratio decreased with cinnamon oil and cinnamaldehyde (Figure 4). Juven et al. (1994) already reported that the antimicrobial effect of cinnamon oil increased as $\mathrm{pH}$ decreased from 6.5 to 5.5. Results indicate that cinnamon oil and cinnamaldehyde have the potential to improve nutrient utilization in the rumen, but in beef production systems, the effects may be more relevant in feeding conditions that favor low ruminal $\mathrm{pH}$.

\section{Anethol}

Anethol (1-methoxy-4-propenylbenzene; $\mathrm{C}_{10} \mathrm{H}_{12} \mathrm{O}$ ) is the main active component of anise ( $P$. anisum) oil and is responsible for its antimicrobial activity, which has been related to the ether group on its aromatic ring (Figures 1 and 2; Davidson and Naidu, 2000). In vitro studies with rumen fluid showed that anethol and anise oil $(2.2 \mathrm{mg} / \mathrm{L})$ decreased total VFA and the proportions of acetate and propionate, and increased the proportion of butyrate, although anethol had stronger effects compared with anise oil. Anise oil and anethol did not affect the ammonia $\mathrm{N}$ concentration (Busquet et al., 2005c). In contrast, Cardozo et al. (2004) suggested that lower doses of anise oil $(0.22 \mathrm{mg} / \mathrm{L})$ in continuous culture stimulated protein degradation, increasing the concentration of peptides and ammonia $\mathrm{N}$, but they reported no effects on the VFA profile. However, when anise oil was used in in vitro fermentation studies with rumen fluid from beef cattle fed a 10:90 forage-to-concentrate diet and $\mathrm{pH} 5.5$, the ammonia $\mathrm{N}$ concentration and acetate proportion decreased, and the propionate proportion increased without affecting total VFA production (Cardozo et al., 2005). Cardozo et al. (2006) used anise oil to supplement growing heifers fed a 10:90 forage-toconcentrate diet and reported a trend toward increased DMI. The total VFA concentration was not affected, but the molar proportion of acetate decreased, the molar proportion of propionate increased, and the acetate-topropionate ratio decreased. Anise oil also decreased the ammonia $\mathrm{N}$ concentration and protozoa counts. These results are consistent with previous in vitro trials simulating conditions of beef cattle fed high-concentrate diets (Cardozo et al., 2005). As discussed for other essential oils, low pH may enhance the effect of some active 
Table 3. Effect of 2 doses of monensin, cinnamaldehyde, and garlic oil on VFA concentrations in continuous culture $^{1}$

\begin{tabular}{lcccccccc}
\hline & \multicolumn{7}{c}{ Treatment $^{2}$} \\
\cline { 2 - 7 } Item & Control & MO & MO10 & CIN & CIN10 & GAR & GAR10 & SEM \\
\hline Total VFA, mM & $87.4^{\mathrm{b}}$ & $89.7^{\mathrm{b}}$ & $104.4^{\mathrm{a}}$ & $85.7^{\mathrm{b}}$ & $88.0^{\mathrm{b}}$ & $93.8^{\mathrm{ab}}$ & $94.3^{\mathrm{ab}}$ & 3.28 \\
Individual VFA, mol/100 mol & & & & & & & & \\
Acetate & $61.2^{\mathrm{a}}$ & $60.2^{\mathrm{ab}}$ & $45.9^{\mathrm{d}}$ & $55.8^{\mathrm{c}}$ & $57.0^{\mathrm{bc}}$ & $58.5^{\mathrm{abc}}$ & $46.8^{\mathrm{d}}$ & 0.94 \\
Propionate & $20.5^{\mathrm{d}}$ & $22.4^{\mathrm{cd}}$ & $45.1^{\mathrm{a}}$ & $24.2^{\mathrm{bc}}$ & $21.6^{\mathrm{cd}}$ & $22.6^{\mathrm{cd}}$ & $27.4^{\mathrm{b}}$ & 1.24 \\
Butyrate & $10.8^{\mathrm{c}}$ & $10.3^{\mathrm{c}}$ & $4.3^{\mathrm{d}}$ & $13.1^{\mathrm{bc}}$ & $14.3^{\mathrm{b}}$ & $11.3^{\mathrm{bc}}$ & $19.4^{\mathrm{a}}$ & 1.47 \\
BCVFA $^{3}$ & $1.0^{\mathrm{a}}$ & $0.9^{\mathrm{bc}}$ & $0.6^{\mathrm{d}}$ & $0.9^{\mathrm{a}}$ & $1.1^{\mathrm{a}}$ & $1.0^{\mathrm{a}}$ & $0.7^{\mathrm{cd}}$ & 0.03 \\
Acetate:propionate & $3.0^{\mathrm{a}}$ & $2.7^{\mathrm{ab}}$ & $1.0^{\mathrm{d}}$ & $2.3^{\mathrm{b}}$ & $2.6^{\mathrm{ab}}$ & $2.6^{\mathrm{ab}}$ & $1.7^{\mathrm{c}}$ & 0.14 \\
\hline
\end{tabular}

${ }^{\mathrm{a}-\mathrm{d}}$ Means within a row with different superscripts differ $(P<0.05)$.

${ }^{1}$ Adapted from Busquet et al. (2005a).

${ }^{2} \mathrm{MO}=1.25 \mathrm{mg} / \mathrm{L}$ of monensin $\mathrm{MO} 10=12.5 \mathrm{mg} / \mathrm{L}$ of monensin; $\mathrm{CIN}=31.2 \mathrm{mg} / \mathrm{L}$ of cinnamaldehyde; CIN10 $=312.0 \mathrm{mg} / \mathrm{L}$ of cinnamaldehyde; GAR $=31.2 \mathrm{mg} / \mathrm{L}$ of garlic oil; GAR10 $=312.0 \mathrm{mg} / \mathrm{L}$ of garlic oil.

${ }^{3} \mathrm{BCVFA}=$ branched-chain VFA (includes isobutyrate and isovalerate).

components of essential oils because of conformational changes in their structure and the higher sensibility of bacteria to these molecules (Skandamis and Nychas, 2000). Our results suggest that anise oil inhibited deamination of AA and reduced the acetate-to-propionate ratio in the rumen, and may be beneficial for beef production systems.

\section{Garlic Oil}

Garlic oil is a mix of a large number of different molecules that are found in the plant or as the result of changes occurring during oil extraction and processing, including sulfur compounds (thiosulfinates, allyl sulfides, glutamylcysteines, allicin), enzymes, free AA, sterols, steroids, triterpenoid glycosides, flavonoids, phenols, and organoselenium compounds (Lawson, 1996). Although garlic oil is known for its therapeutic properties (antiparasitic, insecticidal, anticancer, antioxidant, inmunomodulatory, anti-inflammatory, hypoglycemic), its antimicrobial activity against a wide spectrum of gram-positive and gram-negative bacteria is its most prominent activity and has been thoroughly studied (Reuter et al., 1996). However, its potential effect on modifying rumen microbial fermentation has not been researched until recently. Busquet et al. (2005a,b,c, 2006) consistently showed in in vitro fermentation trials with rumen fluid that garlic oil reduced the proportions of acetate and BCVFA, and increased the proportions of propionate and butyrate (Table 3 ). This fermentation profile is different from that of monensin (which reduces the acetate-to-propionate ratio and butyrate concentration) and is consistent with changes observed when methane inhibitors are supplied to rumen microbes (Chalupa et al., 1980; Martin and Macy, 1985). In fact, in vitro studies demonstrated that garlic reduced the $\mathrm{CH}_{4}(\mu \mathrm{mol})$ :VFA ( $\left.\mu \mathrm{mol}\right)$ ratio from 0.20 to
0.05 (Busquet et al., 2005b). Methane is the main hydrogen sink in the metabolic pathway of rumen fermentation, and inhibition of its synthesis generates reducing equivalents that need to be disposed of, with propionate and butyrate being the main alternatives (Van Nevel and Demeyer, 1988). Garlic oil is a complex mix of many different compounds present in the plant or derived from processing. To identify the main active component in garlic oil, the oil and 4 purified active components (allicin, diallyl sulfide, diallyl disulfide, and allyl mercaptan) thought to play a major role in its antimicrobial activity were tested in vitro to determine their effect on rumen microbial fermentation (Busquet et al., 2005b). Garlic oil, diallyl disulfide, and allyl mercaptan reduced acetate and methane proportions and increased propionate and butyrate proportions to the same extent, suggesting that diallyl disulfide and allyl mercaptan were responsible for most of its effects. In contrast, allicin and diallyl sulfide had minor effects on rumen microbial fermentation (Table 4). The antimicrobial activity of garlic has generally been attributed to its organosulfur compounds, particularly to allicin (Ankri and Mirelman, 1999). However, pure allicin is a very reactive volatile molecule that is rapidly converted to other compounds under various conditions, rendering it inactive under physiological conditions (Lawson, 1996). The effects of garlic oil and its main active components on $\mathrm{N}$ metabolism were more variable. Although Cardozo et al. (2004) reported that garlic oil in continuous culture reduced ammonia $\mathrm{N}$ and increased peptide and AA $\mathrm{N}$ concentrations, suggesting that deamination was inhibited, others have reported only small and variable effects (Busquet et al., 2005a,b). Ferme et al. (2004) reported that garlic modified the microbial population profile in a continuous culture experiment, reducing the contribution of Prevotella spp. (mainly P. ruminantium and $P$. bryantii) to the overall microbial population in 
Table 4. Effects of garlic oil and 4 purified active components on the molar proportions of acetate, propionate, and butyrate ${ }^{1}$

\begin{tabular}{lccccccc}
\hline & \multicolumn{7}{c}{ Treatment, ${ }^{2} 300 \mathrm{mg} / \mathrm{L}$} \\
Item, \\
\cline { 2 - 6 } mol/100 mol & Control & GAR & DAS & DAD & ALM & ALL & SEM \\
\hline Acetate & 65.3 & $58.5^{*}$ & 64.3 & $58.4^{*}$ & $59.4^{*}$ & 65.1 & 0.39 \\
Propionate & 17.3 & $20.1^{*}$ & $14.1^{*}$ & $20.3^{*}$ & $19.9^{*}$ & 17.5 & 0.28 \\
Butyrate & 13.1 & $16.9^{*}$ & 12.9 & $16.6^{*}$ & $16.0^{*}$ & 13.2 & 0.48 \\
\hline
\end{tabular}

${ }^{1}$ Adapted from Busquet et al. (2005b).

${ }^{2} \mathrm{GAR}=$ garlic oil DAS = diallyl sulfate; DAD = diallyl disulfate; ALM = allyl mercaptan; ALL = allicin.

*Means differed from the control $(P<0.05)$.

the rumen. Prevotella spp. are mainly responsible for protein degradation and AA deamination, suggesting a mechanism of action of garlic oil on protein metabolism. However, it is also possible that the reduction in deamination relates to a reduction in the availability of dehydrogenases: Deamination requires the activity of dehydrogenases, and the low dehydrogenase activity observed when methane inhibitors are used (Hino and Russell, 1985) may partly explain the slight reduction in deamination of AA observed with garlic oil.

Most of the studies reported previously were conducted in vitro using rumen fluid from dairy cattle and $60 \%$ alfalfa hay: $40 \%$ concentrate diets designed to meet dairy cattle requirements. Cardozo et al. (2005) tested the effects of garlic oil in vitro using rumen fluid and 10\% straw:90\% corn-barley-based diets formulated for beef cattle at different $\mathrm{pH}(7.0$ vs. 5.5). Whereas at $\mathrm{pH}$ 7.0 garlic oil resulted in lower ammonia $\mathrm{N}$ and total VFA concentrations, at $\mathrm{pH} 5.5$ the ammonia N concentration was also reduced, but the total VFA concentration and propionate proportion increased, and the acetate proportion and acetate-to-propionate ratio decreased compared with a control with no garlic, suggesting a shift in rumen microbial fermentation. The effect of $\mathrm{pH}$ on the response of garlic oil may be related to the dissociated (hydrophilic) or undissociated (hydrophobic) status of the active molecules. Only the undissociated, hydrophobic form of the molecule is able to interact with the lipid bilayer of the cell membrane, diffuse through it, and interact with enzymes in the cytoplasm. As $\mathrm{pH}$ decreases, acids tend to become undissociated and more hydrophobic, thereby interacting more easily with cell membranes and exerting their antimicrobial effect. Furthermore, bacteria seem to be more susceptible to the effects of essential oils at low $\mathrm{pH}$ (Skandamis and Nychas, 2000).

The structure and mechanism of action of garlic oil and its main active components on rumen microbial fermentation are very different from those of all other essential oils. Busquet et al. (2005a,b) suggested that the antimethanogenic effect of garlic and its active components was the result of direct inhibition of Archaea microorganisms in the rumen. Archaea have unique membrane lipids that contain glycerol linked to longchain isoprenoid alcohols essential for the stability of the cell membrane (De Rosa et al., 1986). The synthesis of the isoprenoid units in methanogenic Archaea is catalyzed by hydroxymethylglutaryl coenzyme A (HMGCoA) reductase, an enzyme that has also been described in the liver and that participates in the synthesis of cholesterol. Garlic oil and some derived organosulfur compounds are strong inhibitors of HMG-CoA reductase (Gebhardt and Beck, 1996), and as a result, the synthesis of the isoprenoid unit is inhibited, the membrane of Archaea becomes unstable, and the cells die. Miller and Wolin (2001) provided further support for this hypothesis by demonstrating that lovastatin and mevastatin, which decrease cholesterol production in human liver cells by inhibiting HMG-CoA reductase, specifically inhibit rumen methanogenic Archaea.

\section{Capsaicin}

Capsaicin (8-methyl- $N$-vanillyl-6-nonenamide; $\mathrm{C}_{18} \mathrm{H}_{27} \mathrm{NO}_{3}$ ) is a carotenoid that belongs to the tetraterpenoid group (Cichewicz and Thorpe, 1996). It is found in hot peppers (Capsicum annum ssp.) and is the main component of capsicum oil (10 to 15\%). When supplied to an in vitro culture of rumen fluid from dairy cattle fed a $60 \%$ alfalfa hay and $40 \%$ concentrate diet, the effects in short- and long-term fermentations have been negligible (Cardozo et al., 2004; Busquet et al., 2005c). The lack of effect could be explained by the low number of oxygen molecules in capsaicin, which are directly related to the antimicrobial activity of terpenes (Griffin et al., 1999; Dorman and Deans, 2000). However, Cardozo et al. (2005) demonstrated that the effects were different in an in vitro system with rumen fluid from beef cattle fed a 10:90 straw:concentrate diet, and reported that at $\mathrm{pH} 7.0$, even at moderate doses, total VFA and ammonia $\mathrm{N}$ concentrations were reduced and the acetate-to-propionate ratio was increased. In contrast, at $\mathrm{pH} 5.5$, capsicum oil reduced the ammonia $\mathrm{N}$ concentration, increased total VFA production and the 
propionate proportion, and reduced the acetate proportion and acetate-to-propionate ratio (Figure 4). Therefore, although there seems to be little benefit to capsicum oil for dairy cattle, its effects on high-concentrate diets at low $\mathrm{pH}$ suggest that nutrient utilization in the rumen may be improved. As discussed previously for other essential oils, the low $\mathrm{pH}$ may shift the molecule to a more hydrophobic status, becoming more active as an antimicrobial.

Cardozo et al. (2006) tested the effect of feeding capsicum oil on ruminally canulated beef cattle fed a 10:90 forage:concentrate diet. The total VFA concentration was not affected, but the molar proportion of acetate decreased. Capsicum oil reduced the ruminal concentration of large peptides and increased that of small peptides and AA, but it had no effect on ammonia $\mathrm{N}$ concentrations. These effects suggest that it stimulated peptidolysis, which may provide more peptides and AA, and enhance microbial protein synthesis and flow to the small intestine. Although these changes were in the same direction as the in vitro study (Cardozo et al., 2005), the effects were smaller. Even though Cardozo et al. (2005) reported that capsicum oil reduced the ammonia $\mathrm{N}$ concentration, this effect was not always consistent (Cardozo et al., 2004; Busquet et al., 2005c). In addition to the effects on rumen fermentation, capsicum oil increased DMI and water intake, which may be beneficial in periods when intake may be compromised (arrival to feedlots, heat stress, etc.). There is evidence that capsaicin increases DMI and water intake in rats and humans (Calixto et al., 2000; Zafra et al., 2003), although the effects are likely unrelated to changes in the digestion process. Therefore, there seems to be potential for using capsaicin in beef cattle diets based on its effects in increasing DMI and potential effects on rumen microbial fermentation.

\section{Other Active Components}

Other active components of essential oils have also been tested for their effects on rumen microbial fermentation. Antraquinone (9,10-dioxoanthracene; $\mathrm{C}_{14} \mathrm{H}_{8} \mathrm{O}_{2}$ ) is the main active component of aloe (Aloe succtrina) and senna (Senna alexandria) oils. Garcia-Lopez et al. (1996) demonstrated in vitro and Kung et al. (2003) demonstrated in vivo the ability of anthraquinone to inhibit methane production. This effect appears to be related to the ability of anthraquinone to inhibit the transfer of electrons during the reduction of methyl coenzyme A into methane. However, the reduction in methane production occurred together with an increase in the concentration of hydrogen, which would not result in a recovery of energy in VFA for its utilization by the animal.
Carvacrol [2-methyl-5-(1-methylethyl)phenol; $\left.\mathrm{C}_{6} \mathrm{H}_{3} \mathrm{CH}_{3}(\mathrm{OH})\left(\mathrm{C}_{3} \mathrm{H}_{7}\right)\right]$ is a phenolic compound similar to thymol found in oregano (Origanum spp.) and thyme (Thymus spp.) that has strong antimicrobial activity. Busquet et al. (2005c) reported that in vitro, carvacrol $(2.2 \mathrm{mg} / \mathrm{L})$ decreased large peptide concentrations and increased ammonia $\mathrm{N}$ concentrations at $2 \mathrm{~h}$ after feeding, suggesting that carvacrol either inhibited proteolysis or stimulated peptide lyses. Higher doses $(300 \mathrm{mg} /$ $\mathrm{L}$ ) increased the $\mathrm{pH}$ and butyrate proportion, and decreased the acetate and propionate proportions and total VFA concentration. Similar to the response observed with thymol, it is likely that carvacrol is too strong and nonspecific against microorganisms to have selective effects on rumen microbes. Other active components tested in vitro include limonene, guaiacol, vanillin, carvacrol, benzyl salicylate, and carvone (Cardozo et al., 2004, 2005; Busquet et al., 2005c, 2006; Castillejos et al., 2006), but their effects were small and inconsistent, and have not been studied further.

\section{Combinations of Essential Oils}

The additive, synergistic, and antagonistic effects of combined essential oils have been reported previously (Burt, 2004). Many commercial products on the market have combined one or more essential oils, but very limited research is available on the potential synergies among them. A blend of essential oils (BEO) containing thymol, eugenol, vanillin, and limonene, among other compounds (Rossi, 1999) has been studied for its effects in vitro and in vivo. Several studies in situ (Molero et al., 2004; Newbold et al., 2004) observed that BEO inhibited protein degradation, although the changes reported were small and variable depending on the feed being degraded, the type of ration fed to the animals, and the length of the adaptation period. McIntosh et al. (2003) tested the proteolytic, peptidolytic, and deaminase activity of ruminal fluid of dairy cows supplemented during 4 wk with $1 \mathrm{~g} / \mathrm{d}$ of BEO and observed no effects on proteolytic or peptidolytic activity, but ammonia production from CN degradation decreased; they concluded that BEO was likely inhibiting a specific group of gram-positive bacteria generally called hyperammonia-producing bacteria. This hypothesis was confirmed when McIntosh et al. (2003) observed that pure cultures of hyperammonia-producing bacteria, such as Clostridium sticklandi and Peptstreptococcus anaerobius, were very sensitive to the addition of BEO. However, other ammonia-producing bacteria such as Prevotella ruminicola, Butyrivibrio fibrisolvens, or Clostridium aminophilum were less sensitive to BEO. Wallace et al. (2002) also reported that ammonia production and hyperammonia-producing bacteria decreased in sheep 
fed this BEO in a low-protein diet. These effects were associated with a decrease in the microbial colonization of protein feeds. Most studies that have evaluated the effects of BEO on rumen microbial fermentation have not observed effects on the synthesis of microbial protein (McIntosh et al., 2000; Wallace et al., 2002). Castillejos et al. $(2005,2007)$ observed in vitro that BEO increased total VFA production and the acetate proportion. More recently, Benchaar et al. (2006) reported that feeding this BEO to dairy cattle increased ruminal $\mathrm{pH}$ and $\mathrm{ADF}$ digestion, but had no effects on VFA, N metabolism, protozoa counts, or animal performance.

The combination of cinnamaldehyde and eugenol has also been tested for its effects on rumen fermentation. Cardozo et al. (2006) reported that the combination of cinnamaldehyde $(180 \mathrm{mg} / \mathrm{d})$ plus eugenol $(90 \mathrm{mg} / \mathrm{d})$ reduced total DMI and water intake in beef cattle. The reduction in DMI was also observed in dairy cattle supplemented with high doses of cinnamaldehyde (500 mg/ d; Busquet et al., 2003) and may be related to palatability problems, suggesting that the product needs to be encapsulated to overcome this problem. However, the cinnamaldehyde plus eugenol treatment had no effects on total and individual VFA concentrations except for BCVFA, which tended to be lower. This reduction in BCVFA, together with an increase in the concentrations of small peptides and AA and a decrease in the concentration of ammonia $\mathrm{N}$, suggests that the cinnamaldehyde plus eugenol treatment inhibited deamination of AA. This reduction in deamination is consistent with results observed in vitro with clove bud, eugenol, and cinnamaldehyde (Busquet et al., 2005a,c; Cardozo et al., 2005). Entodinium spp. counts tended to decrease, and Isotricha spp. counts increased $3 \mathrm{~h}$ after feeding, suggesting that the cinnamaldehyde plus eugenol treatment had some effect on protozoa populations. It is likely that the limited effects of cinnamaldehyde and eugenol on rumen microbial fermentation were related to the relatively low dose used. In a second experiment using canulated beef cattle, Cardozo et al. (2006) fed cinnamaldehyde and eugenol encapsulated to prevent effects on DMI and at 3 times the dose fed in their previous study $(600 \mathrm{mg} / \mathrm{d}$ of cinnamaldehyde and 300 $\mathrm{mg}$ of eugenol). Intake of DM was not affected, suggesting that encapsulation was successful in preventing the palatability problems reported in previous studies (Busquet et al., 2003; Cardozo et al., 2006). Furthermore, the effects of higher doses were more apparent; the total VFA concentration was not affected by treatments, but the molar proportion of acetate decreased and the molar proportion of propionate increased. The cinnamaldehyde plus eugenol treatment resulted in the accumulation of small peptides and AA and the reduction of BCVFA and ammonia $\mathrm{N}$ concentrations, sug- gesting that it inhibited deamination activity. The antiprotozoal effect of the cinnamaldehyde plus eugenol treatment was confirmed by the reduction in Entodinium spp. and Isotricha spp. counts $3 \mathrm{~h}$ after feeding, in agreement with the previous trial. These results are encouraging in the development of alternative products to ionophores for beef cattle, but other compounds or mixes may provide similar or better results.

\section{FUTURE RESEARCH NEEDS}

Considerable knowledge has been gained in recent years on the potential use of essential oils to modify rumen microbial fermentation. However, several issues need to be addressed before specific recommendations for commercial use can be established. Some of the limitations of current knowledge that need to be resolved include the following:

1) Because the concentration of active components in essential oils can vary widely depending in the cultivar, growing conditions, or processing methods for oil extraction (Sivropoulou et al., 1996; Marino et al., 2001; Burt, 2004), and to avoid inconsistent results that would create confusion in the literature, researchers should report the concentrations of the main active components in essential oils or should use pure active components, and recommended doses should be established in units ( $\mathrm{mg} / \mathrm{kg}$ or $\mathrm{mg} / \mathrm{head}$ per $\mathrm{d}$ ) of active components rather than units of the oil or extract.

2) In vitro studies have been very useful in screening the effects of a wide variety of essential oils, and will still be useful in the screening of other extracts and to study specific mechanisms of action. However, the limitations of these methods need to be taken into account. Among others, doses used in vitro, generally reported as milligrams per liter, are much higher than those reported to work in in vivo conditions. This is likely because the activity of these compounds depends on the probability of the active component interacting with the target (bacteria), which depends on the concentration of the active component, the concentration of bacteria, and the formation of microenvironments within the rumen. Because the bacterial concentration in vitro is lower than that found in vivo, in vitro tests require a higher concentration of the product (Chow et al., 1994). A clear example of this problem occurs with monensin, for which the effective dose for dairy cattle (185 to $660 \mathrm{mg} / \mathrm{d}$; FDA, 2005), which would correspond to 1.8 to $6.6 \mathrm{mg} / \mathrm{L}$ in a $100-\mathrm{L}$ rumen, is much lower than the $12 \mathrm{mg} / \mathrm{L}$ reported to have an effect in vitro (Busquet et al., 2005a). Furthermore, the complexity of the compartmentalized ecosystem of the rumen requires that recommended doses for animals be tested in vivo. 
3) The microbial ecosystem may adapt to new environmental conditions. Several reports have suggested that an adaptation to the antimicrobial activity of essential oils may occur with time (Cardozo et al., 2004; Molero et al., 2004; Castillejos et al., 2007). In vitro batch studies, in which the adaptation time is short, may discard a product that would work if enough adaptation time had been allowed, but at the same time, a product that is selected based on its short-term effect may not work after a period of adaptation (Cardozo et al., 2004). Therefore, in vivo studies should be conducted with enough time to allow for such adaptations to occur.

4) There are opportunities to explore other effects in rumen fermentation, such as potential effects on biohydrogenation of fatty acids and activity against pathogens, including the enteropathogenic strain Escherichia coli $\mathrm{O} 157: \mathrm{H} 45$.

5) As with any additive, the presence of residues in the product (meat or milk) should be evaluated. No such experiments have yet been conducted.

6) The use of any feed additive can only be justified if there is a beneficial effect larger than the cost of the product. This ratio will depend on the cost of the essential oil, the dose required, and the resulting improvement in animal performance. Although this can only be resolved with animal performance studies, the number of published reports on cattle performance is very limited.

\section{CONCLUSIONS}

Most essential oils and active components tested at high doses have inhibited rumen microbial fermentation, confirming their antimicrobial activity. In most cases, when the concentration of the active component in in vitro rumen fluid fermentation tests was increased to more than $500 \mathrm{mg} / \mathrm{L}$, the effects were detrimental. At moderate doses (between 50 and $500 \mathrm{mg} / \mathrm{L}$, depending on the active compound), some essential oils and their active components were able to modify rumen fermentation by changing VFA production, protein metabolism, or both. In general terms, the reduction in the acetate-to-propionate ratio and the increase in butyrate concentration observed as a result of supplementation with some essential oils or their active components suggest that the main mechanism of action is the inhibition of methanogenesis. In terms of protein metabolism, the mechanism of action may be related to the inhibition of deamination, although the inhibition of peptidolysis has also been suggested for some essential oils. However, a universal extract that works under different conditions may not exist because effects have been diet and $\mathrm{pH}$ dependent. This is reasonable if we assume that neither the bacterial population in such conditions (high-forage vs. high-concentrate diets, high $\mathrm{pH}$ vs. low $\mathrm{pH}$, etc.) nor the objectives of rumen manipulation (dairy vs. beef cattle) are the same. Based on the mechanisms of action of different additives on nutrient degradation and fermentation in the rumen, it is possible to identify potential synergies. A clear definition of the effects and target activities to modify, and a careful selection and combination of essential oils or their active components to modify these activities may provide a useful tool to improve the efficiency of nutrient utilization in the rumen. However, the limited scientific information available on their effects and mechanisms of action may result in confusion and inappropriate use of products and doses. Garlic oil, cinnamaldehyde, eugenol, anethol, and capsaicin are potential options for application as additives for ruminants. However, even though in vitro research is still needed for screening new products and determining mechanisms of action, there is an urgent need to conduct in vivo studies to determine the optimal dose in units of the active component, the potential adaptation of rumen microflora to the action of these additives, the fate of these products in the animal and the presence of residues in meat or milk, and the effects on animal performance.

\section{REFERENCES}

Ankri, S., and D. Mirelman. 1999. Antimicrobial properties of allicin from garlic. Microbes Infect. 2:125-129.

Balandrin, M. F., and J. A. Klocke. 1985. Natural plant chemicals: Sources of industrial and medicinal materials. Science 228:1154-1160.

Benchaar, C., H. V. Petit, R. Berthiaume, T. D. Whyte, and P. Y. Chouinard. 2006. Effects of addition of essential oils and monensin premix on digestion, ruminal fermentation, milk production, and milk composition in dairy cows. J. Dairy Sci. 89:4352-4364.

Borchers, R. 1965. Proteolytic activity of rumen fluid in vitro. J. Anim. Sci. 24:1033-1038.

Broderick, G. A., and J. E. Balthrop. 1979. Chemical inhibition of amino acid deamination by ruminal microbes in vitro. J. Anim. Sci. 49:1101-1111.

Broudiscou, L. P., Y. Papon, and A. F. Broudiscou. 2002. Effects of dry plant extracts on feed degradation and the production of rumen microbial biomass in a dual outflow fermenter. Anim. Feed Sci. Technol. 101:183-189.

Broudiscou, L. P., Y. Papon, and A. F. Broudiscou. 2000. Effects of dry plant extracts on fermentation and methanogenesis in continuous culture of rumen microbes. Anim. Feed Sci. Technol. 87:263-277.

Burt, S. 2004. Essential oils: Their antibacterial properties and potential applications in foods-A review. Int. J. Food Microbiol. 94:223-253.

Busquet, M., S. Calsamiglia, A. Ferret, P. W. Cardozo, and C. Kamel. 2005a. Effects of cinnamaldehyde and garlic oil on rumen microbial fermentation in a dual flow continuous culture. J. Dairy Sci. 88:2508-2516.

Busquet, M., S. Calsamiglia, A. Ferret, M. D. Carro, and C. Kamel. 2005b. Effect of garlic oil and four of its compounds on rumen microbial fermentation. J. Dairy Sci. 88:4393-4404.

Busquet, M., S. Calsamiglia, A. Ferret, and C. Kamel. 2006. Plant extracts affect in vitro rumen microbial fermentation. J. Dairy Sci. 89:761-771. 
Busquet, M., S. Calsamiglia, A. Ferret, and C. Kamel. 2005c. Screening for the effects of natural plant extracts and secondary plant metabolites on rumen microbial fermentation in continuous culture. Anim. Feed Sci. Technol. 123/124:597-613.

Busquet, M., H. Greathead, S. Calsamiglia, A. Ferret, and C. Kamel. 2003. Efecto del extracto de ajo y el cinemaldehido sobre la producción, composición y residuos en leche en vacas de alta producción. ITEA 24 (Vol. Extra):756-758.

Calixto, J. B., A. Beirith, J. Ferreira, A. R. S. Santos, V. C. Filho, and R. A. Yunes. 2000. Naturally occurring antinociceptive substances from plants: A review. Phytother. Res. 14:401-418.

Calsamiglia, S., L. Castillejos, and M. Busquet. 2006. Alternatives to antimicrobial growth promoters in cattle. Pages 129-167 in Recent Advances in Animal Nutrition. P. C. Garnsworthy, and J. Wiseman, ed. Nottingham University Press, Nottingham, UK.

Cardozo, P. W., S. Calsamiglia, A. Ferret, and C. Kamel. 2006. Effects of alfalfa extract, anise, capsicum and a mixture of cinnamaldehyde and eugenol on ruminal fermentation and protein degradation in beef heifers fed a high concentrate diet. J. Anim. Sci. 84:2801-2808.

Cardozo, P. W., S. Calsamiglia, A. Ferret, and C. Kamel. 2004. Effects of natural plant extracts on protein degradation and fermentation profiles in continuous culture. J. Anim. Sci. 82:3230-3236.

Cardozo, P. W., S. Calsamiglia, A. Ferret, and C. Kamel. 2005. Screening for the effects of natural plant extracts at different $\mathrm{pH}$ on in vitro rumen microbial fermentation of a high-concentrate diet for beef cattle. J. Anim. Sci. 83:2572-2579.

Castillejos, L., S. Calsamiglia, and A. Ferret. 2006. Effect of essential oils active compounds on rumen microbial fermentation and nutrient flow in in vitro systems. J. Dairy Sci. 89:2649-2658.

Castillejos, L., S. Calsamiglia, A. Ferret, and R. Losa. 2007. Effects of dose and adaptation time of a specific blend of essential oils compounds on rumen fermentation. Anim. Feed Sci. Technol. 132:186-201.

Castillejos, L., S. Calsamiglia, A. Ferret, and R. Losa. 2005. Effects of a specific blend of essential oil compounds and the type of diet on rumen microbial fermentation and nutrient flow from a continuous culture system. Anim. Feed Sci. Technol. 119:29-41.

Chalupa, W., W. Corbett, and J. R. Brethour. 1980. Effects of monensin and amicloral on rumen fermentation. J. Anim. Sci. 51:170-179.

Chao, S. C., and D. G. Young. 2000. Screening for inhibitory activity of essential oils on selected bacteria, fungi and viruses. J. Essent. Oil Res. 12:639-649.

Chow, J. M., J. A. S. Van Kessel, and J. B. Russell. 1994. Binding of radiolabeled monensin and lasolacid to ruminal microorganisms and feed. J. Anim. Sci. 72:1630-1635.

Cheeke, P. R. 1999. Actual and potential applications of Yucca schidigera and Quillaja saponaria saponins in human and animal nutrition. Proc. Am. Soc. Anim. Sci. E9:1-10.

Cichewicz, R. H., and P. A. Thorpe. 1996. The antimicrobial properties of chile peppers (Capsicum species) and their uses in Mayan medicine. J. Ethnopharmacol. 52:61-70.

Cimanga, K., K. Kambu, L. Tona, S. Apers, T. Bruyne, N. Hermans, J. Totté, L. Pieters, and A. J. Vlietinck. 2002. Correlation between chemical composition and antibacterial activity of essential oils of some aromatic medicinal plants growing in the Democratic Republic of Congo. J. Ethnopharmacol. 79:213-220.

Cox, S. D., C. M. Mann, and J. L. Markam. 2001. Interaction between components of the essential oil of Melaleuca alternifolia. J. Appl. Microbiol. 91:492-497.

Davidson, P. M., and A. S. Naidu. 2000. Phyto-phenols. Pages 265293 in Natural Food Antimicrobial Systems. A. S. Naidu, ed. CRC Press, Boca Raton, FL.

Deans, S. G., and G. Ritchie. 1987. Antibacterial properties of plant essential oils. Int. J. Food Microbiol. 5:165-180.

De Rosa, M., A. Gambacorta, and A. Gliozzi. 1986. Structure, biosynthesis, and physicochemical properties or archaebacterial lipids. Microbiol. Rev. 50:70-80.

Dorman, H. J. D., and S. G. Deans. 2000. Antimicrobial agents from plants: Antibacterial activity of plant volatile oils. J. Appl. Microbiol. 88:308-316.
Evans, J. D., and S. A. Martin. 2000. Effects of thymol on ruminal microorganisms. Curr. Microbiol. 41:336-340.

FDA (US Food and Drug Administration). 2005. Freedom of information summary. Supplemental new animal drug application. NADA 095-735. Monensin Sodium (Rumensin 80): Type A Medicated Article for Dairy Cattle. http://www.fda.gov/cvm/FOI/095735s121505.pdf Accessed Oct. 1, 2006.

Feldberg, R. S., S. C. Chang, A. N. Kotik, M. Nadler, Z. Neuwirth, D. C. Sundstrom, and N. H. Thompson. 1988. In vitro mechanism of inhibition of bacterial cell growth by allicin. Antimicrob. Agents Chem. 32:1763-1768.

Ferme, D., M. Banjac, S. Calsamiglia, M. Busquet, C. Kamel, and G. Avgustin. 2004. The effects of plant extracts on microbial community structure in a rumen-simulating continuous-culture system as revealed by molecular profiling. Folia Microbiol. (Praha) 49:151-155

Garcia-Lopez, P. M., L. Kung, Jr., and J. M. Odom. 1996. In vitro inhibition of microbial methane production by 9,10 -anthraquinone. J. Anim. Sci. 74:2276-2284.

Gebhardt, R., and H. Beck. 1996. Differential inhibitory effects of garlic-derived organosulfur compounds on cholesterol biosynthesis in primary rat hepatocyte cultures. Lipids 31:1269-1276.

Gershenzon, J., and R. Croteau. 1991. Terpenoids. Pages 165-219 in Herbivores: Their Interactions with Secondary Plant Metabolites. Vol. 1. G. A. Rosenthal, and M. R. Berenbaum, ed. Academic Press, San Diego, CA.

Griffin, S. G., S. G. Wyllie, J. L. Markham, and D. N. Leach. 1999. The role of structure and molecular properties of terpenoids in determining their antimicrobial activity. Flavour Fragr. J. 14:322-332.

Gustafson, R. H., and R. E. Bowen. 1997. Antibiotic use in animal agriculture. J. Appl. Microbiol. 83:531-541.

Gutiérrez, M. E., A. F. García, M. A. de Madariaga, M. L. Sagrista, F. J. Casadó, and M. Mora. 2003. Interaction of tocopherols and phenolic compounds with membrane lipid components: Evaluation of their antioxidant activity in a liposomal model system. Life Sci. 72:2337-2360.

Hammer, K. A., C. F. Carson, and T. V. Riley. 1999. Antimicrobial activity of essential oils and other plant extracts. J. Appl. Microbiol. 86:985-990.

Harborne, J. B., and C. A. Williams. 2000. Advances in flavonoid research since 1992. Phytochemistry 55:481-504.

Helander, I. M., H. Alakomi, K. Latva-Kala, T. Mattila-Sandholm, I. Pol, E. J. Smid, L. G. M. Gorris, and A. Wright. 1998. Characteritzation of the action of selected essential oil components on gram-negative bacteria. J. Agric. Food Chem. 46:3590-3595.

Hino, T., and J. B. Russell. 1985. Effect of reducing-equivalent disposal and NADH/NAD on deamination of amino acids by intact rumen microorganisms and their cell extracts. Appl. Environ. Microbiol. 50:1368-1374.

Hoffmann, C., and C. A. Evans. 1911. The use of spices as preservatives. J. Ind. Eng. Chem. 3:835-838.

Horton, G. M. J. 1980. Use of feed additives to reduce ruminal methane production and deaminase activity in steers. J. Anim. Sci. 50:1160-1164.

Juven, B. J., J. Kanner, F. Schved, and H. Weisslowicz. 1994. Factors that interact with the antibacterial action of thyme essential oil and its active constituents. J. Appl. Bacteriol. 76:626-631.

Kamel, C. 2001. Tracing modes of action and the roles of plant extracts in non-ruminants. Pages 135-150 in Recent Advances in Animal Nutrition. P. C. Garnsworthy, and J. Wiseman, ed. Nottingham University Press, Nottingham, UK.

Kung, L., Jr., K. A. Smith, A. M. Smalaga, K. M. Endress, C. A. Bessett, N. K. Ranjit, and J. Yaissle. 2003. Effects of 9,10 anthraquinine on ruminal fermentation, total-tract digestion, and blood metabolite concentrations in sheep. J. Anim. Sci. 81:323-328.

Lawson, L. 1996. The composition and chemistry of garlic cloves and processed garlic. Pages 37-107 in Garlic: The Science and Therapeutic Application of Allium sativum L. and Related Species. H. P. Koch, and L. D. Lawson, ed. Williams \& Wilkins, Baltimore, MD. 
Lee, S. E., H. J. Hwang, J. S. Ha, H. S. Jeong, and J. H. Kim. 2003. Screening of medicinal plant extracts for antioxidant activity. Life Sci. 73:167-179.

Mahmoud, A. L. E. 1994. Antifungal action and antiaflatoxigenic properties of some essential oil constituents. Lett. Appl. Microbiol. 19:110-113.

Marino, M., C. Bersani, and G. Comi. 2001. Impedance measurements to study the antimicrobial activity of essential oils from Lamiacea and Compositae. Int. J. Food Microbiol. 67:187-195.

Martin, S. A., and J. M. Macy. 1985. Effects of monensin, pyromellitic diimide and 2-bromoethanesulfonic acid on rumen fermentation in vitro. J. Anim. Sci. 60:544-550.

McIntosh, F. M., C. J. Newbold, R. Losa, P. Williams, and R. J. Wallace. 2000. Effects of essential oils on rumen fermentation. Reprod. Nutr. Dev. 40:221-222.

McIntosh, F. M., P. Williams, R. Losa, R. J. Wallace, D. A. Beever, and C. J. Newbold. 2003. Effects of essential oils on ruminal microorganisms and their protein metabolism. Appl. Environ. Microbiol. 69:5011-5014.

Miller, T. L., and M. J. Wolin. 2001. Inhibition of growth of methaneproducing bacteria of the ruminant forestomach by hydroxymethylglutaryl SCoA reductase inhibitors. J. Dairy Sci. 84:1445-1448.

Min, B. R., T. N. Barry, G. T. Attwood, and W. C. McNabb. 2003. The effect of condensed tannins on the nutrition and health of ruminants fed fresh temperature forages: A review. Anim. Feed Sci. Technol. 106:3-19.

Mohammed, N., N. Ajisaka, Z. A. Lila, K. Mikuni, K. Hara, S. Kanda, and H. Itabashi. 2004. Effect of Japanese horseradish oil on methane production and ruminal fermentation in vitro and in steers. J. Anim. Sci. 82:1839-1846.

Molero, R., M. Ibars, S. Calsamiglia, A. Ferret, and R. Losa. 2004 Effect of a specific blend of essential oil compounds on dry matter and crude protein degradability in heifers fed diets with different forage to concentrate rations. Anim. Feed Sci. Technol. 114:91104

Nagy, J. G., and R. P. Tengerdy. 1968. Antibacterial action of essential oils of Artemisia as an ecological factor. II. Antibacterial action of the volatile oils of Artemisia tridentata (big sagebrush) on bacteria from the rumen of mule deer. Appl. Microbiol. 16:441444.

Newbold, C. J., F. M. McIntosch, P. Williams, R. Losa, and R. J. Wallace. 2004. Effects of a specific blend of essential oil compounds on rumen fermentation. Anim. Feed Sci. Technol. 114:105-112.

Nikaido, H. 1994. Prevention of drug access to bacterial targets: Permeability barriers and active efflux. Science 264:382-388.

European Commission. 2003. Regulation (EC) No. 1831/2003 of the European Parliament and of the Council of 22 September 2003 on Additives for Use in Animal Nutrition. Off. J. Eur. Union L:L268/29-L268/43.

O'Gara, E. A., D. J. Hill, and D. J. Maslin. 2000. Activities of garlic oil, garlic powder, and their diallyl constituents against Helicobacter pylori. Appl. Environ. Microbiol. 66:2269-2273.

Oh, H. K., M. B. Jones, and W. M. Longhurst. 1968. Comparison of rumen microbial inhibition resulting from various essential oils isolated from relatively unpalatable plant species. Appl. Microbiol. 16:39-44.

Oh, H. K., T. Sakai, M. B. Jones, and W. M. Longhurst. 1967. Effect of various essential oils isolated from Douglas fir needles upon sheep and deer rumen microbial activity. Appl. Microbiol. 15:777-784.

Ouattara, B., R. E. Simard, R. A. Holley, G. J.-P. Piette, and A. Bégin. 1997. Antibacterial activity of selected fatty acids and essential oils against six meat spoilage organisms. Int. J. Food Microbiol. 37:155-162.

Pentz, R., and C. P. Siegers. 1996. Methods for qualitative and quantitative assessment of their ingredients. Pages 109-134 in Garlic: The Science and Therapeutic Application of Allium sativum L. and Related Species. H. P. Koch, and L. D. Lawson, ed. Williams \& Wilkins, Baltimore, MD.

Piacente, S., C. Pizza, and W. Oleszek. 2005. Saponins and phenolics of Yucca schidigera Roezl: Chemistry and bioactivity. Phytochem. Rev. 4:177-190.

Piva, G., and F. Rossi. 1999. Possible alternatives to the use of antibiotics as growth promoters. New additives. In Feed Manufacturing in the Mediterranean Region. Opt. Mediter. 37:83-106.

Prescott, L. M., J. P. Harley, and D. A. Klein. 2004. Control de microorganismos por agentes físicos y químicos. Pages 145-162 in Microbiología. McGraw-Hill-Interamericana de España, Madrid, Spain.

Reddy, L., B. Odhav, and K. D. Bhoola. 2003. Natural products for cancer prevention: A global perspective. Pharmacol. Therap. 99:1-13.

Reuter, H. D., J. P. Koch, and L. Lawson. 1996. Therapeutic effects and applications of garlic and its preparations. Pages 135-212 in Garlic: The Science and Therapeutic Application of Allium sativum L. and Related Species. H. P. Koch, and L. D. Lawson. ed. Williams \& Wilkins, Baltimore, MD.

Ross, Z. M., E. A. O'Gara, D. J. Hill, H. V. Sleightholme, and D. J. Maslin. 2001. Antimicrobial properties of garlic oil against human enteric bacteria: Evaluation of methodologies and comparisons with garlic oil sulfides and garlic powder. Appl. Environ. Microbiol. 67:475-480.

Rossi, J. 1999. Additives for animal nutrition and technique for their preparation. European Patent EP 0646321 B1.

Sangwan, N. S., A. H. A. Farooqi, F. Shabih, and R. S. Sangwan. 2001. Regulation of essential oil production in plants. Plant Growth Reg. 34:3-21.

Sikkema, J., J. A. M. Bont, and B. Poolman. 1994. Interactions of cyclic hydrocarbons with biological membranes. J. Biol. Chem. 269:8022-8028.

Sivropoulou, A., E. Papanikolaou, C. Nikolaou, S. Kokkini, T. Lanaras, and M. Arsenakis. 1996. Antimicrobial and cytotoxic activities of Origanum essential oils. J. Agric. Food Chem. 44:12021205.

Skandamis, P. N., and G. J. Nychas. 2000. Development and evaluation of a model predicting the survival of Escherichia coli O157:H17 NCTC 12900 in homemade eggplant salad at various temperatures, $\mathrm{pHs}$, and oregano essential oil concentration. Appl. Environ. Microbiol. 66:1646-1653.

Smith-Palmer, A., J. Stewart, and L. Fyfe. 1998. Antimicrobial properties of plant essential oils and essences against five important food-borne pathogens. Lett. Appl. Microbiol. 26:118-122.

Tamminga, S. 1996. A review on environmental impacts of nutritiona strategies in ruminants. J. Anim. Sci. 74:3112-3124.

Trouillas, P., C. A. Calliste, D. P. Allais, A. Simon, A. Marfak, C. Delage, and J. L. Duroux. 2003. Antioxidant, anti-inflammatory and antiproliferative properties of sixteen water plant extracts used in the Limousin countryside as herbal teas. Food Chem. 80:399-407.

Ultee, A., M. H. J. Bennik, and R. Moezelaar. 2002. The phenolic hydroxyl group of carvacrol is essential for action against the food-borne pathogen Bacillus cereus. Appl. Environ. Microbiol. 68:1561-1568.

Ultee, A., E. P. Kets, and E. J. Smid. 1999. Mechanisms of action of carvacrol on the food-borne pathogen Bacillus cereus. Appl. Environ. Microbiol. 65:4606-4610.

Van Nevel, C. J., and D. I. Demeyer. 1988. Manipulation of rumen fermentation. Pages 387-443 in The Rumen Microbial Ecosystem. P. N. Hobson, ed. Elsevier Applied Science, New York, NY.

Wallace, R. J., N. R. McEwan, F. M. McIntosh, B. Teferedegne, and C. J. Newbold. 2002. Natural products as manipulators of rumen fermentation. Asian-australas. J. Anim. Sci. 10:1458-1468.

Wendakoon, C. N., and M. Sakaguchi. 1995. Inhibition of amino acid decarboxylase activity of Enterobacter aerogenes by active components in spices. J. Food Prot. 58:280-283.

Zafra, M. A., F. Molina, and A. Puerto. 2003. Effects of perivagal administration of capsaicin on post-surgical food intake. Auto. Neurosci.: Basic and Clin. 107:37-44. 